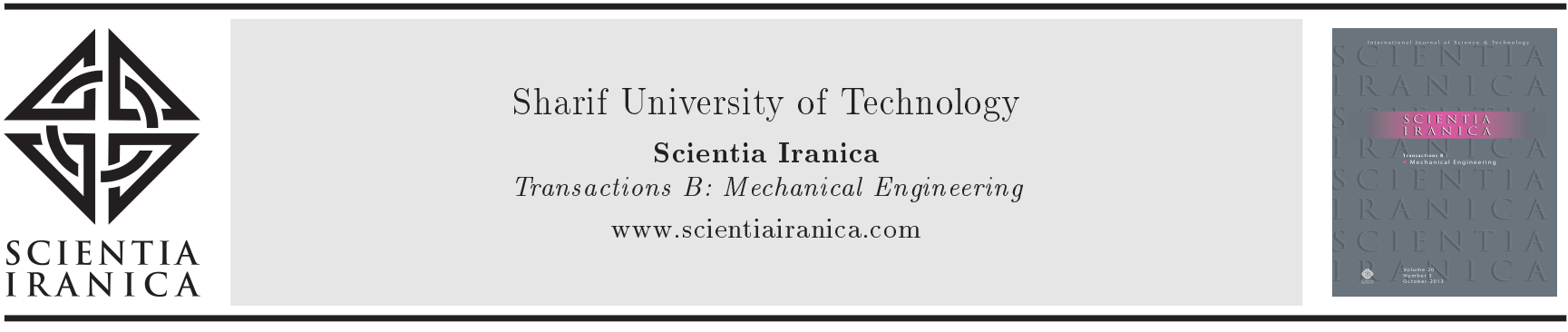

\title{
Surface modification of biomaterial embedded with pits using die sinker machine
}

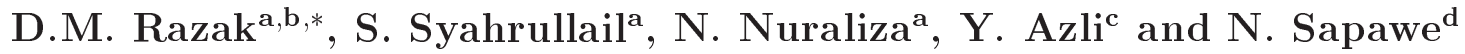 \\ a. Department of Thermo-Fluids, Faculty of Mechanical Engineering, Universiti Teknologi Malaysia, 81310 UTM Johor Bahru, \\ Johor, Malaysia. \\ b. Department of Mechanical Engineering, Politeknik Tuanku Sultanah Bahiyah, 09000 Kulim, Kedah, Malaysia. \\ c. Department of Biotechnology and Medical Engineering, Faculty of Biosciences and Medical Engineering, Universiti Teknologi \\ Malaysia, 81310 UTM Johor Bahru, Johor, Malaysia. \\ d. Institute of Chemical and Bioengineering Technology, Universiti Kuala Lumpur-, Melaka, Malaysia.
}

Received 23 September 2014; received in revised form 22 July 2015; accepted 26 September 2016

\section{KEYWORDS}

Surface modification;

Pit;

Biomaterial;

Die sinker;

Tribology.

\begin{abstract}
Surface modification has been applied in many ways to enhance exclusive implant product. Electrical Discharge Machine Die Sinker (EDM DS) is a new approach to machine a macro surface on the biomaterial. In this study, investigations of current properties of EDM DS to obtain a new surface in titanium alloy (Ti-6Al-4V) and stainless steel (E-316-L), which placed pit on the material-sized $(25 \mathrm{~mm})$ diameter sample with a radius of $6.3 \mathrm{~mm}$, were conducted. All the samples of concave textured circular pits with a fixed diameter and depth of $0.5 \mathrm{~mm}$ were successfully machined. This study revealed that the pits were produced in the concave cup and the lubricant was confined inside the pits, making easier contact between metal ball and metal concave surface. The results also show that the discharge machine is an attractive machining method for surface modification of biomaterial. This paper suggests that concave implant surface embedded with pits will work as a trap for lubricant and wear debris; in addition, it is possible to increase the lifespan of implant structure.
\end{abstract}

(C) 2017 Sharif University of Technology. All rights reserved.

\section{Introduction}

Nowadays, there are many effective uses of biomaterial for equipment and devices in medical prosthesis. Biomaterial is currently the most successful and reliable orthopedic operation and has been reported to improve the patient's damaged health, especially for severe hip damage $[1,2]$. Biomaterial designed for implant must have osteoblast activity, osseointegration, proliferation and may reduce the adhesion [2-5]. Spark plasma sintering is one method that improved the properties of implant material [6-10]. Hence, in order to increase

\footnotetext{
*. Corresponding author. Tel.: +6016 509 7432;

Fax: +607556 6159

E-mail address: mrazak3@live.utm.my (D.M. Razak)
}

the level of resistance and longevity of the biomaterial (prosthetic), high-powered machine, such as Computer Numerical Control Electrical Discharge Machine Die Sinker (CNC EDM DS), is needed to machine pits on the biomaterial surface, as shown Figure 1. Discharge machine or spark erosion disintegration using pulsed electrical discharge is known as a non-conventional machining procedure to evacuate, to a great degree, hard and fragile materials which cannot be machined with ordinary procedures.

EDM, appropriate for highly accurate and very sophisticated metal shaping, was inferred by Behrens and Ginzel [11]. Other researchers claimed that EDM's current setting may influence the material surface and cause different roughness of surfaces [12]. On micro EDM, many researchers describe the characteristics, 


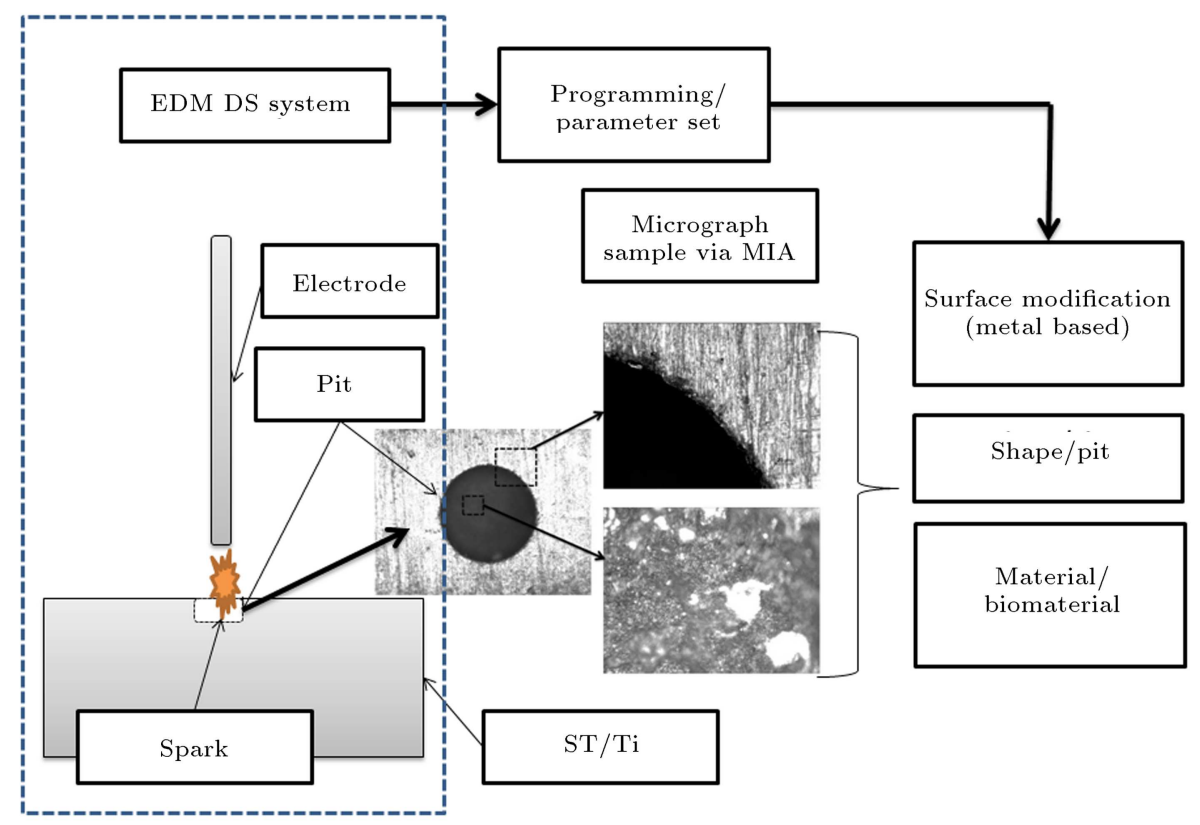

Figure 1. The EDM die sinker flow process to machine pit of concave cup.

parameters of Metal Removal Rate (MRR), and tool wear which are essential in a micro-EDM process. Since EDM is a non-contact process, the change of the current between the electrode and workpiece is important in an EDM process. Liu et al. [13] showed that micro EDM has the capabilities to fabricate a small hole in nickel alloy used to prevent interference of the magnetic field. Yan et al. used EDM to produce a circular micro-tool with high-aspect ratio in borosilicate glass [14]. Nowadays, EDM DS is also used in precision machining for medical parts, aerospace parts, and other highly-specialized products. Nikhil et al. reported that EDM DS is widely used for machining hard material with high precision, high surface finish, and complex profiles. EDM also has advantages where it can reduce environmental pollution [15].

The existence of pit approach in biomaterials may open new fields in other areas such as automotive, medical, and so on. Treated surface or production of micro-sized pit may be helpful as an oil reservoir of fluid. The existence of fluid is bound to reduce friction on the surface. Previous studies have found that surface treatment serves to improve tribological properties whose effect decreases debris particle or metallosis [16-18]. Nevertheless, to produce a uniform pit (uniform depth), the use of press machine, conventional lathe machine, is limited to the type of machine tool, time machining, and so on [19]. Hence, several machining methods, such as electroforming, chemical milling, ultrasonic machining, laser machining, electrobeam machining, and electrical discharge machining, known as non-traditional machining processes, were introduced as alternative methods in order to improve the quality of the machined materials. EDM DS may be able to machine a very hard material (high HRC) and can be molded as required with minor crack [20-22]. With the working concept of EDM, unit of Material Removal Rate (MRR) is in microns, without any severe damage to the surface (micro-cracking) based on voltage and current parameter setting.

The focus of this study is to machine pits on biomaterial using EDM DS concept. After a decade, without a perforated surface, biomaterial may have severe damage and uncontrolled lubrication. Machining curvature surface of hard biomaterial using conventional machines can cause broken tool bit, high chip or burr, material losses, and less efficiency [22-26]. For this purpose, a pit (known as oil pockets, holes, dimples or cavities) is machined on the concave cup in which trapping lubrication in the implant surface has to be found.

\subsection{Materials and methods}

There are two types of biomaterials, titanium alloy (Ti-6Al-4V) and stainless steel (E-316-L), for medical products, such as active implants and prosthesis. All samples have a round shape with $25 \mathrm{~mm}$ diameter curve at the center with a radius of $6.25 \mathrm{~mm}$, and pit fabricated at $1.0 \pm 0.1 \mathrm{~mm}$. This concave model discharged sparks to produce the pits in a circular arrangement, with each pit design machined to 8 pits (single circular pattern in Figure 2). For this study, the electrode tool is a copper tungsten rod with a radius of $0.5 \mathrm{~mm}$. Copper tungsten electrode with composition of copper (25\%) and tungsten (75\%) was used to machine a pit on the biomaterial. The chemical and mechanical properties of the copper tungsten electrode are indulgent, thus reducing the electrode wear [27]. 


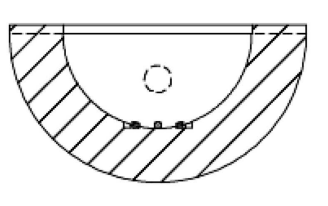

Section A-A
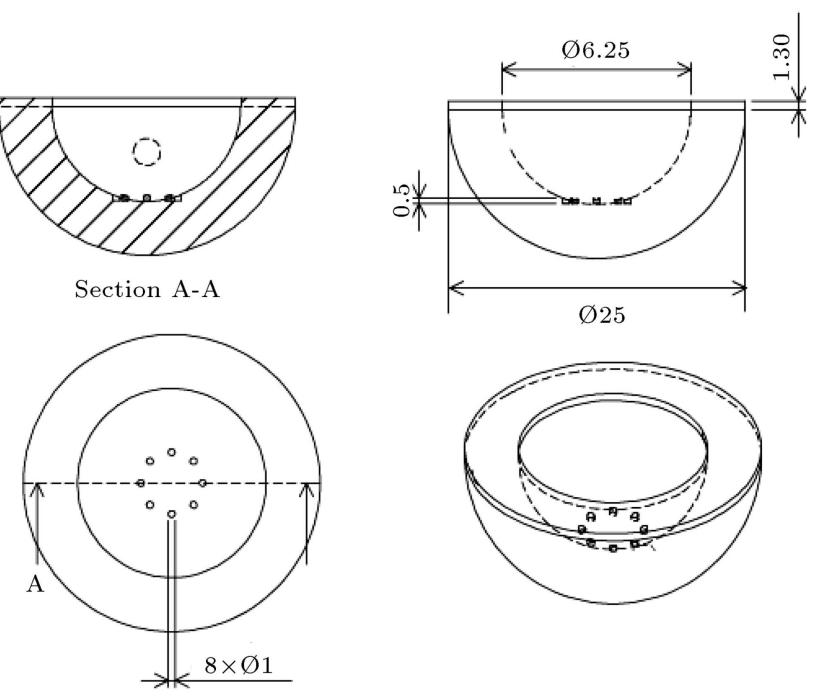

Figure 2. Acetabular cup sample with pit dimension; left-top view and front-right view, illustrating acetabular cup with 8 pits.

\subsection{EDM setup}

In general, various parameters in Electrical Discharge Machine Die Sinker (EDM DS) were considered such as current diameter of electrode $(\varnothing)$, length of retraction gap distance of electrode $\left(Q D_{\text {up }}\right)$, duration of machine head pulse discharge $\left(Q D_{\text {on }}\right)$, discharge on time adjustment $\left(T_{\text {on }}\right)$, off discharge time adjustment $\left(T_{\text {off }}\right)$, and voltage during the EDM process $\left(V_{\text {gap }}\right)$. Compared to other main applications of EDM DS, the experimental condition is preferred to study the level of metal removal and electrode wear [28]. In this experiment, copper tungsten electrode with diameter of $1.0 \mathrm{~mm}$ was selected to machine pits of $0.5 \mathrm{~mm}$ depth or holes of biomaterial used. For the dielectric fluid, Fuchs Ratax EDM was used. The details of the parameter setting of this experiment are shown in Table 1.

For a successful machining, various parameters have to be taken into consideration, especially the current function. In this experiment, the rate of change impacts effects of low-current voltage, LT, and $V$ gaps. The Ratax EDM oil was used as the electrolyte oil according to industrial and commercial grade electrolyte oil. A flow flushing electrolyte oil

Table 1. Experimental condition for EDM DS.

\begin{tabular}{ll}
\hline \multicolumn{1}{c}{ Parameters } & \multicolumn{1}{c}{ Value set } \\
\hline Current, $L T$ & $0.5 \mathrm{~A}, 1.5 \mathrm{~A}, 3.0 \mathrm{~A}$ \\
Diameter electrode, $\varnothing$ & $1.0 \mathrm{~mm}$ \\
$Q D_{\text {up }}$ & $1 \mathrm{~mm}$ \\
$Q D_{\text {on }}$ & $30 \mu \mathrm{s}$ \\
$T_{\text {on }}$ & $0.50 \mu \mathrm{s}$ \\
$T_{\text {off }}$ & $4 \mathrm{stages}=10 \mu \mathrm{s}$ \\
$V_{\text {gap }}$ & $75 \mathrm{~V}$ \\
\hline
\end{tabular}

was applied to ensure that the particle can go out during process $Q_{c p}$ (electrode rises up to $1 \mathrm{~mm}$ ). To acquire surface roughness $(\mathrm{Ra})$ for the finest machining of micro part on the biomaterial, the time was set as follows: for pulse-on time $T_{\text {on }}=0.50 \mu \mathrm{s}$, pulse-off time $T_{\text {off }}=10 \mu \mathrm{s}$, and duration of discharge $Q D_{\text {on }}=30 \mu \mathrm{s}$.

EDM DS ZNC A50 was chosen due to intelligent artificial features that seem to understand the needs of programmers or machine operators. The electrode's initial step was to touch the surface of the workpiece. Once the placement is set, it is configured as coordinates $x o, y o$, and $z o$; By using $x$-axis and $y$-axis coordinates, the position of the cavity and the negative $z$ axis $(-0.5 \mathrm{~mm})$ in depth are determined. After completing the first pit, the electrode was manually lifted or moved to another surface (other axis $x n$, and $y n$ ), and new coordinates were obtained to draw the latest $z$-axis position. At new position $z$, the electrode was brought to the coordinates of the first pit and lowered to touch the surface. Considering the determination of the percentage of the first workpiece with pit depth on certain current, gap setting can be ascertained by looking at the cover. Then, the machine is repeated to determine the depths of the other pieces that are machined. This standard experiment was repeated for materials (stainless steel and titanium alloy) used with different currents $(0.5 \mathrm{~A}, 1.5 \mathrm{~A}$, and $3.0 \mathrm{~A})$ and $V$ gap $(75 \mathrm{~V})$.

EDM oil or dielectric was fed with a flushing pipe while the workpiece was placed close to the magnetic table (see Figure 3). In this experiment, the pits were machined on a circle arrangement. A Microscopy Image Analysis (MIA) was used to examine the pit's inner and outer surfaces; repeat scans were conducted randomly on some of the workpieces observed to ensure fairly good reproducibility. Finally, a successful concave surface was then embedded with 8 pits to investigate pit's effect using 0.5 A current rates with depth $0.5 \mathrm{~mm}$ by this die sinker machine.

In this paper, tribology analysis is focused on the friction coefficient and pit implementation for survival of the concave surface. Results showed that the concave surface embedded with a pit could produce lower coefficient of friction compared to untreated concave sample lubricated with RBD palm olein (RBD PL).

\subsection{Tribology for concave surface}

In this study, to identify the effect of pit application on improving tribological properties, a four-ball tribotester was used followed by the ASTM D4172. The instrument of four-ball wear machine used concave samples with one ball on the top. The concave sample held firmly in a modified ball pot, containing the lubricant being tested, was pressed against the top ball. The top ball was made to rotate at the desired speed, while the bottom three balls were pressed against it, as 


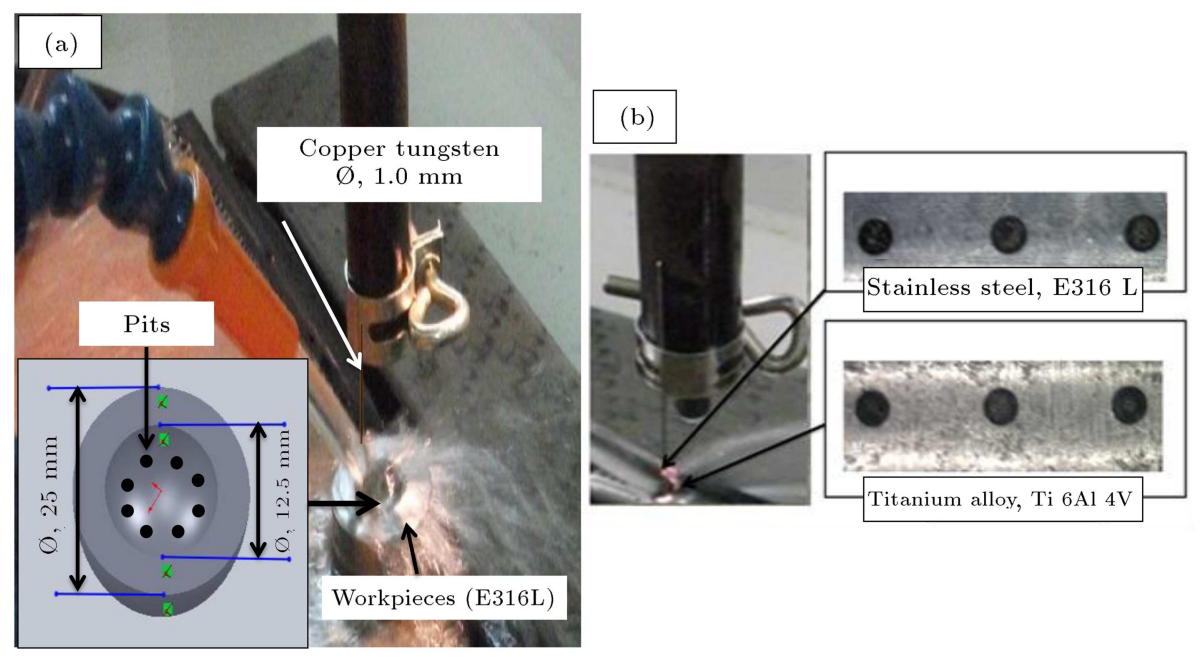

Figure 3. Experimental setup: (a) Dimension of specimens for machining pit on the curvature cup (E316L), and (b) the sample during spark process for stainless steel (E316L) and Titanium alloy, Ti 6Al 4V.

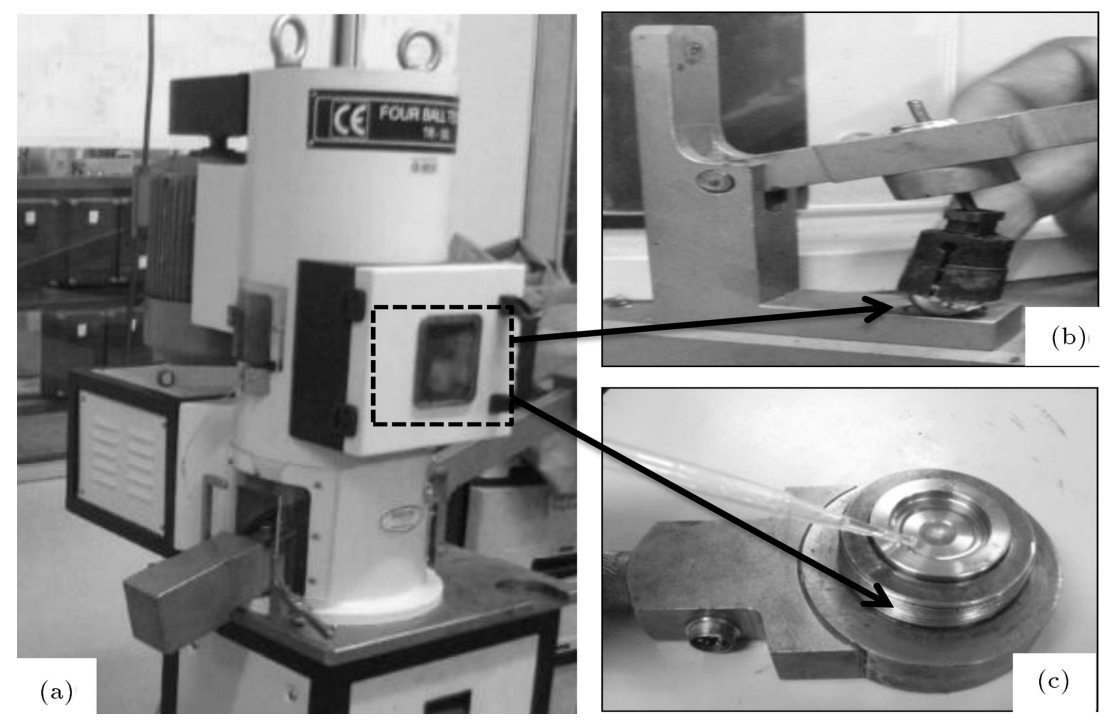

Figure 4. Test equipment: (a) Four-ball tribotester, (b) single ball (chrome alloy steel ball, E316L), and (c) modified ball pot with concave cup (untreated sample).

illustrated in Figure 4. This study method is used to identify tribological properties on the curvature cup in the previous paper [29].

Two types of concave samples with 8 pits embedded and untreated concave sample were used for each test. Concave samples are made of stainless steel (E316-L), and test balls of $12.7 \mathrm{~mm}$ diameter size used in this experiment are made of AISI E-52100 chrome alloy steel (HRC 64) and Extra Polish (EP) with grade 25. For each time before starting a new test, all samples were cleaned with acetone and wiped dry using a fresh lint-free industrial wipe. This research used RBD palm olein as a lubricant produced based on Malaysia standard 816:199, which has a potential application due to a recipe of biodegradability, renewability, and excellent performance in tribology [30-33] . Each trial tested $10 \mathrm{ml}$ of the lubricant. The obtained friction coefficient results of tribology test from untreated concave (flat) sample were compared with those of treated concave sample with 8 pits embedded. It was preferred to obtain an average diameter of machined pits of $0.5 \mathrm{~mm}$ placed at $450^{\circ}$ distances of each other in an array of circles (with radius of $3.9 \mathrm{~mm}$ ).

\section{Results and discussion}

\subsection{Effect of current rates for machining pits on the biomaterial}

It was found that current voltage of EDM DS supplied to the electrode is the major effect of process variables of surface modification on the biomaterial. The improvements concerning biomaterial surface, using EDM DS machined pit on the surface, were changed. Table 2 demonstrates the surface modification of biomaterials 
Table 2. The result of experimental machining pit (Ti and STS).

\begin{tabular}{|c|c|c|c|c|c|c|c|}
\hline Sample & $\begin{array}{l}\boldsymbol{L T} \\
(\mathbf{A})\end{array}$ & Material $^{\mathrm{a}}$ & $\begin{array}{c}\text { Tool } \\
\text { electrode } \\
\text { wear }(\%)\end{array}$ & $\begin{array}{c}\text { Depth } \\
\text { archive } \\
(\%)\end{array}$ & $\begin{array}{l}\text { Time of } \\
\text { machine } \\
\text { (Minute) }\end{array}$ & $\begin{array}{c}\text { Inner surface } \\
\text { evaluation } \\
\text { via } \text { MIA }^{\mathrm{b}}\end{array}$ & $\begin{array}{c}\text { Outliner } \\
\text { surface micro } \\
\text { crack }^{\mathrm{c}}\end{array}$ \\
\hline A & 0.5 & 1 & 11.3 & 99.81 & 1.00 & 1 & 1 \\
\hline B & 1.5 & 1 & 9.2 & 99.82 & 4.53 & 2 & 2 \\
\hline $\mathrm{C}$ & 3.0 & 1 & 8.1 & 99.78 & 1.42 & 2 & 2 \\
\hline $\mathrm{D}$ & 0.5 & 2 & 2.5 & 99.81 & 13.55 & 1 & 1 \\
\hline $\mathrm{E}$ & 1.5 & 2 & 1.7 & 99.72 & 4.44 & 2 & 2 \\
\hline $\mathrm{F}$ & 3.0 & 2 & 1.8 & 99.72 & 2.26 & 2 & 2 \\
\hline
\end{tabular}

${ }^{a}$ Material: 1. Titanium, Ti; 2. Stainless steel (STS).

${ }^{\mathrm{b}}$ Inner surface evaluation via MIA: 1- Super fine; 2- Fair/smooth.

${ }^{\mathrm{c}}$ Outliner surface micro crack: 1- Super fine; 2- Fair/smooth.

as the most affected area observed in the MIA between the two biomaterials used. Many studies were done to improve the implant surface which is economical and more efficient using EDM process [34-36]. Other methods used for surface modification on the biomaterial were explored using plasma-immersion ion and nonthermal electron beam evaporation processing $[37,38]$. In this work, the low current rates $(0.5 \mathrm{~A}-3.0 \mathrm{~A})$ were examined for machining pit of biomaterial using EDM DS between two biomaterials.

From Table 2, a set of data pit on machining at lower currents of $0.5 \mathrm{~A}$ to $3.0 \mathrm{~A}$ was observed using Microscopy Imaging Analysis (MIA). It was found that the depth of machining is almost $0.5 \mathrm{~mm}$, as required for both materials used. Percentage of tool electrode wear was less, which is good compared to polluted waste of materials. Also, inner and outliner parts of the surface show a decrease of micro line (micro crack). The machining of EDM reported that more micro lines will appear with high current [39]. The capability of $\mu$ EDM die sinker to produce micro holes using 80-140 V was also reported by Jafferson [40].

Consequently, once titanium was machined at lower current 0.5 , tool wear and time discharge decreased, but the super fine surface was performed, as seen in Figure 5. This has also occurred for the material stainless steel. Also, the highest current set and the clear biomaterials' surfaces with pit showed the micro line. As demonstrated in Table 2, the outer and inner pit machines of the titanium and stainless steel were found to be clearly smooth, and the micro super fine line was at lower current $0.5 \mathrm{~A}$. Rough surface modification must be avoided due to the possibility of material fatigue and corrosion [41]. Aung reported that good surface quality depends on the controlled machine setting and cutting parameter in EDM [42].

Figures 6 and 7 show the surface profiles of machined titanium alloy and stainless steel, respectively, obtained by computerized numerical EDM DS control and programmed code process. According to

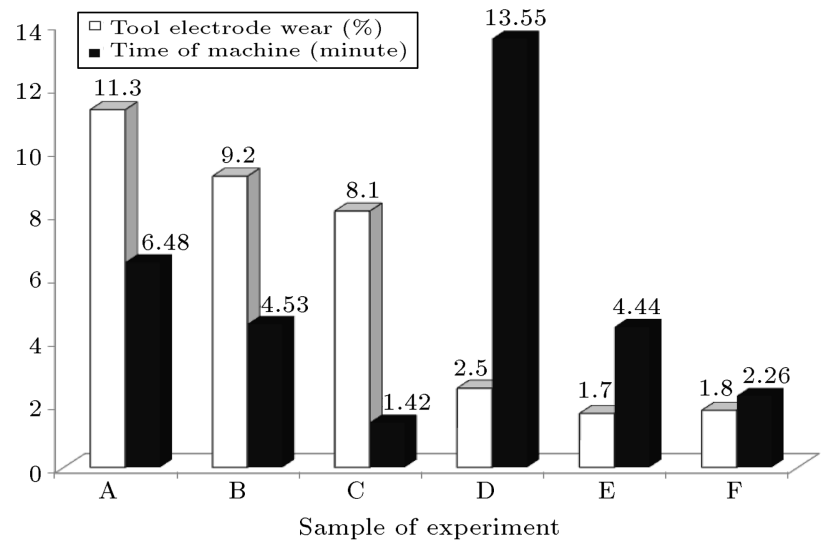

Figure 5. Tool electrode wear and machining time for samples of experiment.

Figures 6 and 7 , left column of the figures illustrates the pit machine, while the top right column shows the inner surface, and the bottom right column shows the outliner surface micrograph of each pit. Based on the observation, an increase in the current became coarser with the current rates $(1.5 \mathrm{~A}$ to $3.0 \mathrm{~A})$. Moreover, under single voltage, $75 \mathrm{~V}$, the flushing pipe was used to ensure the continuity of metal removal. In particular, the setting process achieved a super fine-finishing surface profile under a lower current at $0.5 \mathrm{~A}$, as shown in the micrograph samples, A and D, respectively. However, under higher current at $3 \mathrm{~A}$, the surface micrograph of pit machined was obviously rough on sample $\mathrm{F}$ (stainless steel) compared to sample C (titanium).

The experiment was conducted by machining 18 pits, where the current settings were at $0.5 \mathrm{~A}, 1.5 \mathrm{~A}$, and $3.0 \mathrm{~A}$. This condition was preferred to obtain an average percentage of the pit depth archive, percentage of tool electrode wear, and time of machining pit. The results of both biomaterials in this experiment showed that each pit has been machined at $5 \mathrm{~mm}$ distances of each other in a parallel array. From the result, it was observed that the biomaterials changed the surface 


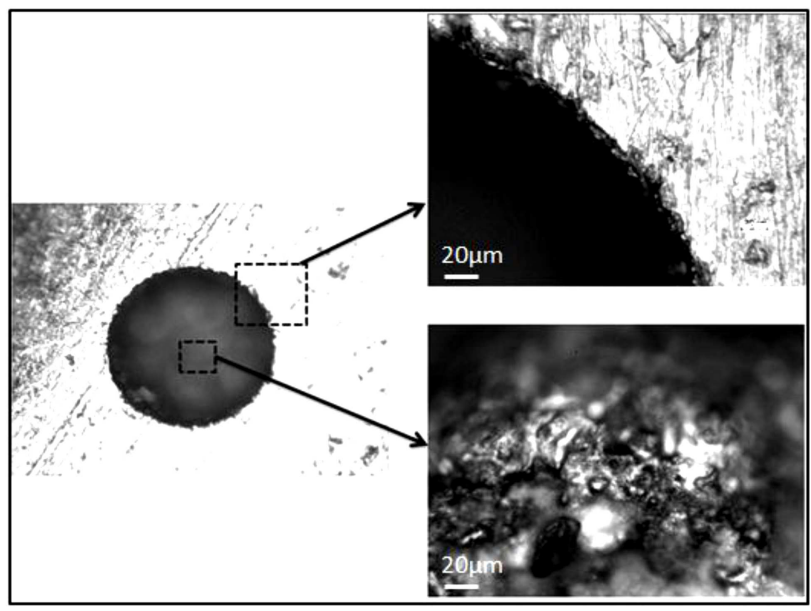

(a) Micrograph of sample A

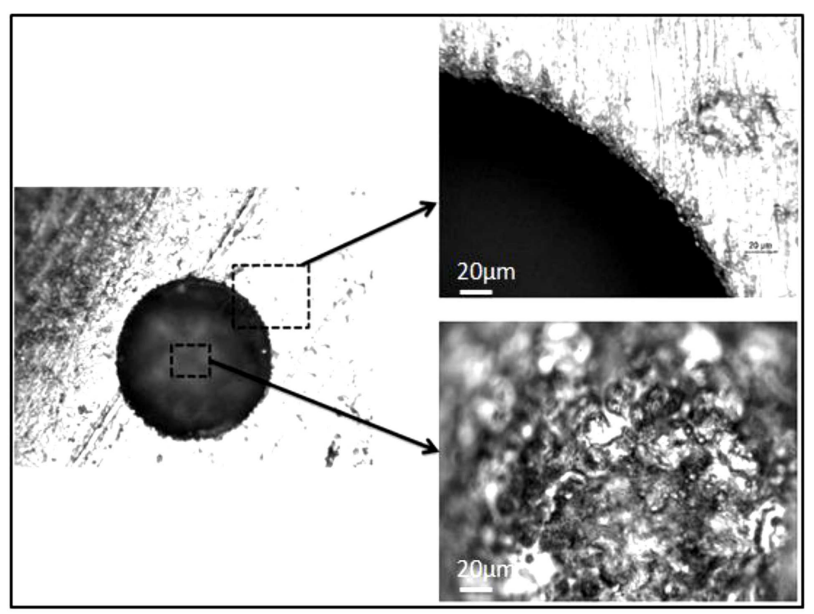

(b) Micrograph of sample B

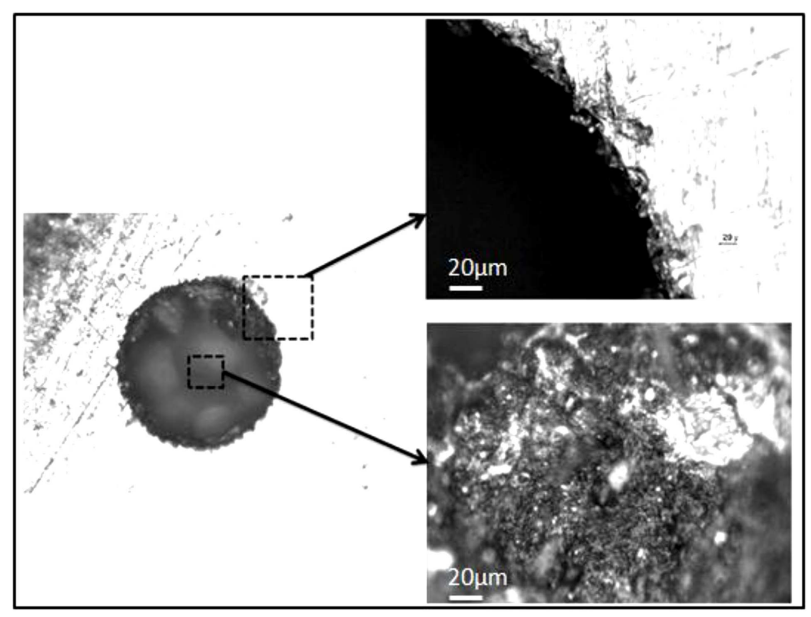

(c) Micrograph of sample C

Figure 6. MIA pits micrographs of stainless steel material of outliner and inner surfaces: (a) and (b) The smooth surface at low current and high magnification for inner and outliner surfaces $(0.5 \mathrm{~A}$ and $1.5 \mathrm{~A})$, respectively, and (c) the rough surface at $3.0 \mathrm{~A}$ and high magnification.

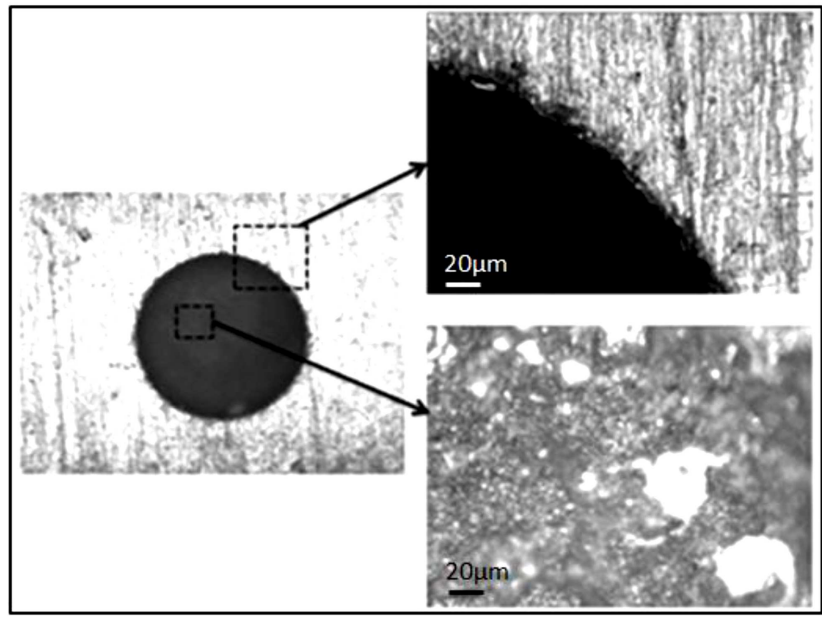

(a) Micrograph of sample D

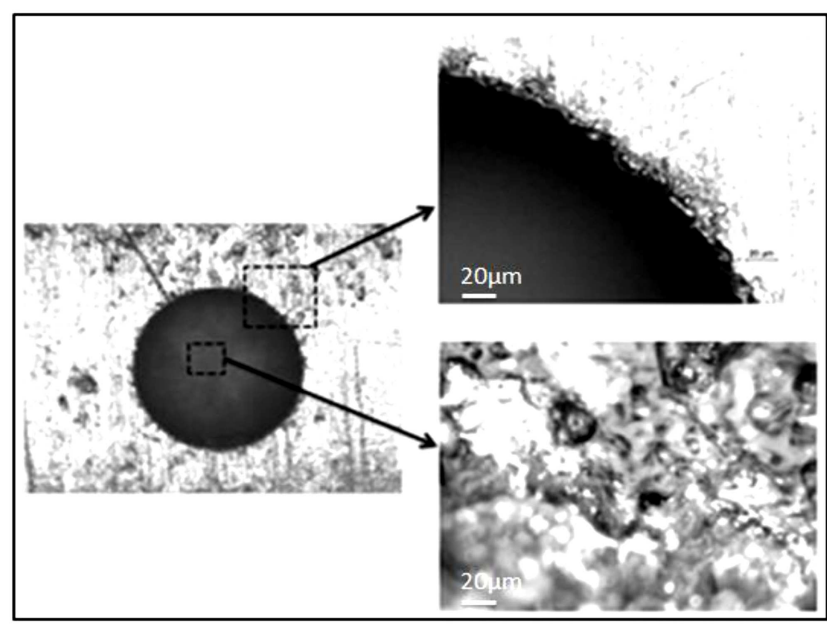

(b) Micrograph of sample E

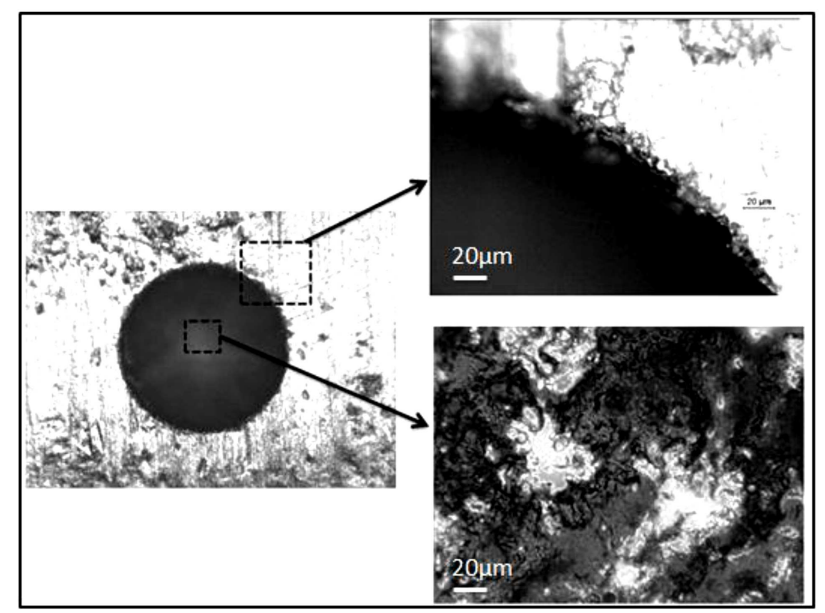

(c) Micrograph of sample F

Figure 7. MIA pits micrographs of Titanium material in outliner and inner surfaces: (a) and (b) The smooth surface at low current and high magnification for inner and outliner surfaces $(0.5 \mathrm{~A}$ and $1.5 \mathrm{~A})$, respectively, and (c) the rough surface at $3.0 \mathrm{~A}$ and high magnification. 
structure at higher current setting, showing more pit outliner sparkline than that at lower current set from flatten surface it. Debris, affected by the spark during machining process, was removed when the high current was applied during the discharge process, as reported by Praveen [43].

In this experiment, the discharge current at $3.0 \mathrm{~A}$ may affect the residue area of workpiece, known as overcut. In EDM, overcut will increase based on high current setting, $T_{\text {on }}$, polarity and $T_{\text {off }}$ [44]. It is shown that the surface modifications made in stainless steel and titanium are apparently compatible with each other, except that they produce titanium within a quicker time. Based on the MIA, micro crack was present, represented by the micro-line length on the surface area of the pit machined (sample A-sample D). It can be concluded that when current-voltage was increased, micro-cracks clearly appeared on the outer side of pit [36]. Meanwhile, a pit inner surface and depth revealed good performance with the flushing rate of electrolytic used as mentioned by Wang, such that the flushing rate has to be optimized during machining for super-fine surface [45].

Analyses from Figures 6 and 7 summarize the relation of inner surface to the current setting in EDM DS, indicating the reduction of surface roughness with a decrease in the current. Then, the micro line gradually increased based on material and current setting during the machining process. Since the machined surface of EDM DS was distributed in various dimensions of parameter, the improvement of surface roughness obviously improved the surface modification $[46,47]$. On the other hand, it might be able to reduce the cost of coating and other surface treatments in biomaterial. Moreover, surface modification with an embedded pit is a new approach that can be produced frequently and easily due to Computer programming on Numerical Control (CNC) technology.

\subsection{Effect of pit on tribological concave surface}

In this experiment, the concave cup (316-L) between treated and untreated surfaces was investigated using die sinker machine. In the present research, the first experimental attempt was carried out with the force acting between the ball and the untreated concave cup as the asperity friction, as shown in Figure 8 (a). At this point, the lubricant was found to be interacting between the femoral head and the acetabular cup. There was no force and sliding speed; thus, there was no pressure contact between ball and the pitted concave cup, and no severe contact was present as in Figure $7(\mathrm{c})$. However, at a force of a normal load $(400 \mathrm{~N})$, the concave cup impoverished the asperity contact, and the contact surface was observed to rub against each other.
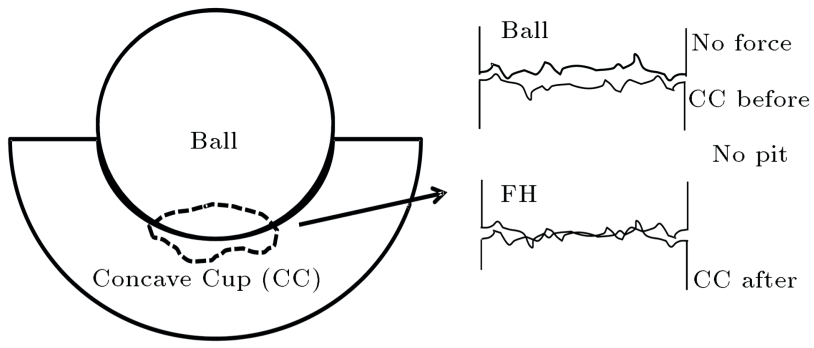

(a)
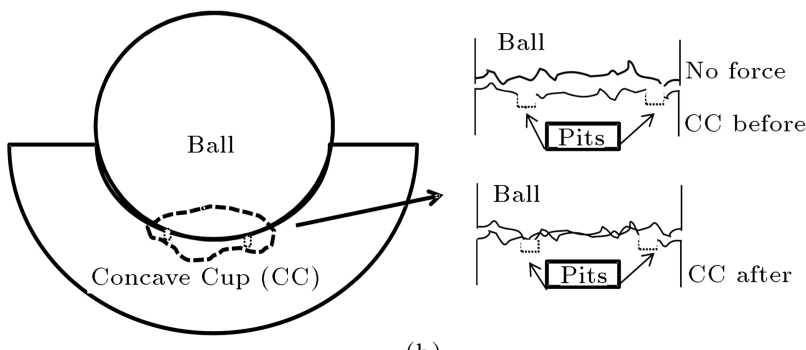

(b)

Figure 8. (a) Regions of a sliding contact between ball and flatten concave cup. (b) Regions of a sliding contact between ball and pitted concave cup.

It was observed that comparison of a damaged surface, or severely worn one presented in Figure 9(a), with the untreated surface (Figure $9(\mathrm{~b})$ ) shows sustainability of concave surface to maintain surface as in the previous test. The application of pits for the concave cup can be seen as a new approach for adding the volume of cup. The amount of pits on the curvature surface that increased the volume of the lubricant trapped can significantly optimize the ball and concave contact. The concept of pits array has been shown as applied to the concave cup, and it provided more hydrodynamic pressure during contact sliding that improved lubricant on the metal contact.

This new approach of using pitted cup and palm oil as a human joint lubricant is very valuable to biodiversity of palm product towards enhancing the lifespan of implant cup. Palm oil products are allergyfree (animal-wise) and more economical due to being readily available. In addition, palm oil is odourless and tasteless and does not require hydrogenation to achieve a solid state. The task of RBD palm oil under sliding conditions is to allow relative motion between steel ball and concave sample surfaces with low friction and no damage to treated surface. This is achieved when the RBD PL film is thick enough to keep worn concave surface. Previous studies established that RBD PL film could reduce wear and friction on surface contact $[32,48-51]$. In this study, the results in Figure 9(a) have demonstrated surface with wear damage for untreated concave sample.

The obtained results on tribological properties of friction torque and surface appearance can make the lifespan of concave sample longer depending on the 

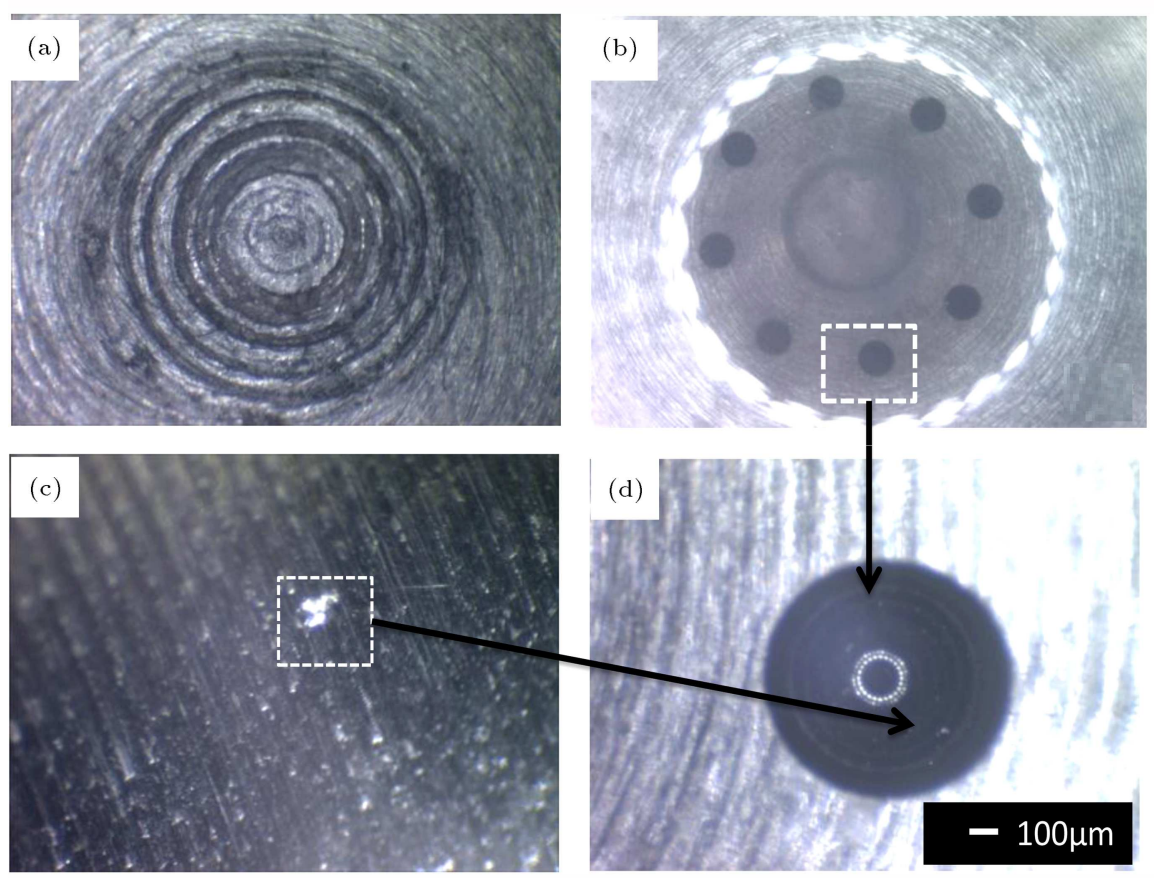

Figure 9. Samples of concave surface after tribology test: (a) Severe untreated concave, (b) treated concave surface embedded with 8 pits assumed as totally smoothed workpiece, (c) wear debris in the pit, and (d) pit trapped debris and acting as oil storage.

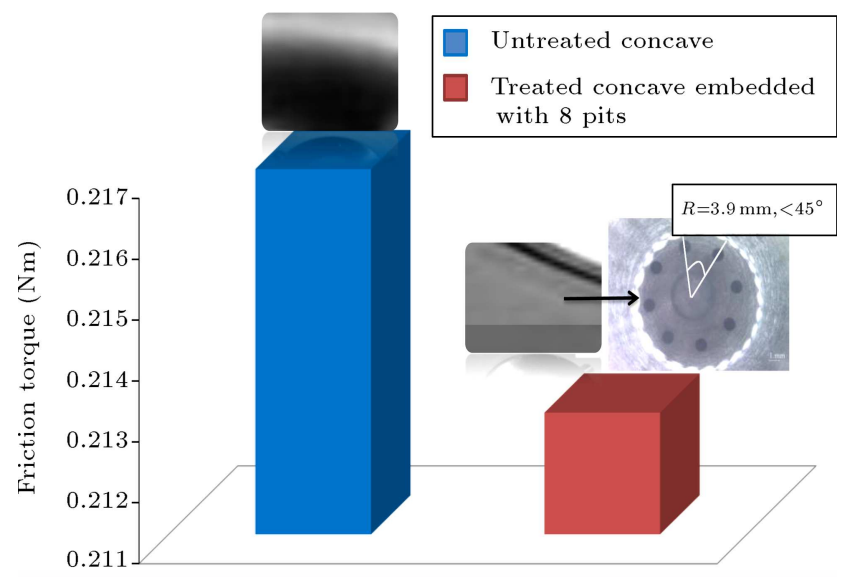

Figure 10. Friction coefficient of untreated and modified concave specimens.

surface modification. Under the same condition as for that sample, flat and modified concave surfaces were tested. Figure 10 shows that the averages of frictional torque against untreated concave and treated samples (modified concave surface embedded with pits) are $0.217 \mathrm{Nm}$ and $0.213 \mathrm{Nm}$, respectively. The results showed that the production of more pits in the hemispherical or curvature cup necessitates the confinement of more lubricant inside the pits; in this way, contact is easier made to the metal ball contact or curvature cup. It is determined that a new approach surface embedded with pits by EDM DS can be utilized for concave biomaterial surface to improve tribology in curvature cup implant.

\section{Conclusion and perspectives}

In summary, we have shown the electrical discharge processing of two types of biomaterials between stainless steel and titanium alloy. They were machined using different low currents to produce pit. Surface of concave cup with pits allow lubrication activities, thus reducing friction and wear in Total Hip Replacement (THR). In order to modify the surface of the biomaterials, the pits machined were shown to have a new character of implant's metal material that mechanically works as an oil reservoir and the pits placed have bright future applications in soft tissue engineering and implant surface. The pits have enhanced the metal-on-metal tribology as well as hip prosthesis and improved concave surface. In a new investigation on biomaterials, machining pit using electro-discharge method will be involved with further evaluation of biomaterial constructs and detailed biocompatibility evaluation of tribological biomaterials. In addition, the effects of the behaviour of the lubricant on the tribological were such that the chemical and physical behaviors allowed the metal concave cup to be treated by the oil-based palm. In this study, only the number of pits embedded in the metal spherical cup based on the metal surface in a circular configuration was examined. Because this area of study is still in its 
infancy, further enhancement of the adhesion strength, friction coefficient and wear in real medical prostheses is recommended. Also, the future simulation studies on concave cup embedded with pits can be conducted to identify its capabilities in the human biology.

\section{Acknowledgement}

The authors would like to express their thanks to Research Management Centre (RMC) of Universiti Teknologi Malaysia for the Research University Grant (GUP-03H58) and Ministry Of Higher Education (MOHE) for financial support. Thanks also to the Mechanical Department of PTSB for the laboratory facilities.

\section{References}

1. Sermon, A., Broos, P. and Vanderschot, P. "Total hip replacement for acetabular fractures, results in 121 patients operated between 1983 and 2003", Injury, 39(8), pp. 914-921 (2008).

2. Divya, R.V.V., Vinoth, K.L., Anitha, V.C., Manzoor, K., Deepthy, M. and Shantikumar, V.N. "Osteointegration of titanium implant is sensitive to specific nanostructure morphology", Acta Biomaterialia, 8, pp. 1976-1989 (2012).

3. Wang, G., Meng, F., Ding, C., Chu, P.K. and Liu, X. "Microstructure, bioactivity and osteoblast behavior of monoclinic zirconia coating with nanostructured surface", Acta Biomaterialia, 6, pp. 990-1000 (2010).

4. Neoh, K.G., Hu, X., Zheng, D. and Kang, E.T. "Balancing osteoblast functions and bacterial adhesion on functionalized titanium surfaces", Biomaterials, 33, pp. 2813-2822 (2012).

5. Hamilton, D.W., Chehroudi, B. and Brunette, D.M. "Comparative response of epithelial cells and osteoblasts to microfabricated tapered pit topographies in vitro and in vivo", Biomaterials, 28, pp. 2281-2293 (2007).

6. Beri, N., Maheshwari, S., Sharma, C. and Kumar, A. "Performance evaluation of powder metallurgy electrode in electrical discharge machining of AISI D2 steel using Taguchi method", Parameters, 110, pp. 19-20 (2008).

7. Lauwers, B., Brans, K., Liu, W., Vleugels, J., Salehi, S. and Vanmeensel, K. "Influence of the type and grain size of the electro-conductive phase on the WireEDM performance of $\mathrm{ZrO}_{2}$ ceramic composites", CIRP Annals- Manufacturing Technology, 57, pp. 191-194 (2008).

8. Huang, S.G., Vanmeensel, K., Van, D.B.O. and Vleugels, J. "In situ synthesis and densification of submicrometergrained B 4 C-TiB composites by pulsed electric current sintering", J. European Ceramic Society, 31, pp. 637-644 (2011).

9. Yang, J., Gu, W., Pan, L.M., Song, K., Chen, X. and Qiu, T. "Friction and wear properties of in situ (TiB $\mathrm{TiC}) / \mathrm{Ti} 3 \mathrm{SiC} 2$ composites", Wear, 271, pp. 29402946 (2011).

10. Chaim, R., Marder, J.R. and Shen, J.Z. "Transparent YAG ceramics by surface softening of nanoparticles in spark plasma sintering", Materials Science and Engineering A, 429, pp. 74-78 (2006).

11. Behrens, A. and Ginzel, J. "Neuro-fuzzy process control system for sinking EDM", J. Manufacturing Processes, 5, pp. 33-39 (2003).

12. Kiyak, M. and Cakir, O. "Examination of machining parameters on surface roughness in EDM of tool steel", J. Mater. Pro. Tech., 191, pp. 141-144 (2007)

13. Liu, H.S., Yan, B.H., Huang, F.Y. and Qiu, K.H. "A study on the characterization of high nickel alloy micro-holes using micro-EDM and their applications", J. Mater. Pro. Tech., 169, pp. 418-426 (2005).

14. Kumar, H.N., Kumar, L. and Yadav, R. "Comparative study for mrr on die-sinking edm using electrode of copper and graphite", Int. J. Adv. Tech. and Eng. Research, 2, pp. 170-174 (2012).

15. Yan, B.H., Wang, A.C., Huang, C.Y. and Huang, F.Y. "Study of precision micro-holes in borosilicate glass using micro EDM combined with micro ultrasonic vibration machining", Int. J. Machine Tools and Manufacture, 42, pp. 1105-1112 (2002).

16. Nasab, M.B. and Hassan, M.R. "Metallic biomaterials of knee and hip-a review", Trends in Biomaterials and Artificial Organs, 24, pp. 69-82 (2010).

17. Mohd, A.N., Solomon, D.G. and Fuad, B.M. "A review on current research trends in electrical discharge machining (EDM)", Int. J. Machine Tools and Manufacture, 47, pp. 1214-1228 (2007).

18. Jawahir, I.S., Brinksmeier, E., Saoubi, R.M., Aspinwall, D.K., Outeiro, J.C., Meyer, D., Umbrello, D. and Jayal, A.D. "Surface integrity in material removal processes, Recent advances", CIRP AnnalsManufacturing Technology, 60, pp. 603-626 (2011).

19. Lauwers, B., Oosterling, H. and Vanderauwera, W. "Development of an operations evaluation system for sinking EDM", CIRP Annals-Manufacturing Technology, 59, pp. 223-226 (2010).

20. Kumagai, S., Naoki, S. and Koichi, T. "Combination of capacitance and conductive working fluid to speed up the fabrication of a narrow, deep hole in electrical discharge machining using a dielectric-encased wire electrode", Int. J. Machine Tools and Manufacture, 12, pp. 1536-1546 (2006).

21. Srivastava, V. and Pandey, P.M. "Effect of process parameters on the performance of EDM process with ultrasonic assisted cryogenically cooled electrode", $J$. Manufacturing Processes, 14, pp. 393-402 (2012). 
22. Sen, M. and Shan, H.S. "A review of electrochemical macro-to micro-hole drilling processes", Int. J. Machine Tools and Manufacture, 45, pp. 137-152 (2005).

23. Brehl, D.E. and Dow, T.A. "Review of vibrationassisted machining", Precision Engineering, 32, pp. 153-172 (2008).

24. Alam, K., Mitrofanov, A.V. and Silberschmidt, V.V. "Measurements of surface roughness in conventional and ultrasonically assisted bone drilling", J. Biomed. Sci., 1, pp. 312-320 (2009).

25. Wan, Z., Li, Y., Tang, H., Deng, W. and Tang, Y. "Characteristics and mechanism of top burr formation in slotting microchannels using arrayed thin slotting cutters", Precision Engineering, 38, pp. 28-35(2014).

26. Arunkumar, N., Rawoof, H.A.S. and Vivek, R. "Investigation on the effect of process parameters for machining of EN31 (Air Hardened Steel) by EDM", Int. J. Eng. Research and Applications, 2, pp. 11111121 (2012).

27. Marafona, J. and Wykes, C. "A new method of optimising material removal rate using EDM with copper-tungsten electrodes", Int. J. Machine Tools and Manufacture, 40, pp. 153-164 (2000).

28. Chakraborty, A., Ray, K.K. and Bhaduri, S.B. "Comparative wear behavior of ceramic and carbide tools during high speed machining of steel", J. Materials and Manufacturing Processes, 15, pp. 269-300 (2000).

29. Daud, M.R., Syahrullail, S., Yahya, A., Mahmud, N., Hashim, N.L.S. and Nugroho, K. "Lubrication on the curve surface structure using palm oil and mineral oil", Procedia Engineering, 68, pp. 607-612 (2013).

30. Pantzaris, T.P., Pocketbook of Palm Oil Uses, Malaysian Palm Oil Board (2002).

31. Fox, N.J. and Stachowiak, G.W. "Vegetable oil-based lubricants - a review of oxidation", Tribology International, 40, pp. 1035-1046 (2007).

32. Syahrullail, S., Kamitani, S. and Nakanishi, K. "Experimental evaluation of refined, bleached, and deodorized palm olein and palm stearin in cold extrusion of aluminum A1050", Tribology Transactions, 55, pp. 199-209 (2012).

33. Ing, T.C., Rafiq, A.K.M., Azli, Y. and Syahrullail, S. "Tribological behaviour of refined bleached and deodorized palm olein in different loads using a four-ball tribometer", Scientia Iranica Transaction B, 19(6), pp. 1487-1492 (2012).

34. Bartolo, P., Kruth, J.P., Silva, J., Levy, G., Malshe, A., Rajurkar, K. and Leu, M. "Biomedical production of implants by additive electro-chemical and physical processes", CIRP Annals-Manufacturing Technology, 61, pp. 635-655 (2012).

35. Li, Y., Jiang, H., Pang, L., Wang, B.A. and Liang, X. "Novel application of nanocrystalline nickel electrodeposit, making good diamond tools easily, efficiently and economically", Surface and Coatings Technology, 201, pp. $5925-5930$ (2007).
36. Bigi, A., Fini, M., Bracci, B., Boanini, E., Torricelli, P., Giavaresi, G. and Giardino, R. "The response of bone to nanocrystalline hydroxyapatitecoated Ti13Nb11Zr alloy in an animal model", Biomaterials, 29, pp. 1730-1736 (2008).

37. Shimizu, M., Sawano, H., Yoshioka, H. and Shinno, H. "Surface texture assessment of ultra-precision machined parts based on laser speckle pattern analysis", Precision Engineering, 38, pp. 1-8 (2014).

38. Lee, E.J., Lee, S.H., Kim, H.W., Kong, Y.M. and Kim, H.E. "Fluoridated apatite coatings on titanium obtained by electron-beam deposition", Biomaterials, 26, pp. 3843-3851 (2005).

39. Garg, R.K., Singh, K.K., Sachdeva, A., Sharma, V.S., Ojha, K. and Singh, S. "Review of research work in sinking EDM and WEDM on metal matrix composite materials", Int J. Adv. Manufacturing Technology, 50, pp. 611-624 (2010).

40. Jafferson, J.M. and Hariharan, P. "Investigation of the quality of microholes machined by $\mu$ edm using image processing", Materials and Manufacturing Processes, 28, pp. $1356-1360$ (2013).

41. Medved, J.J., Breton, M. and Irving, P.E. "Corrosion pit size distributions and fatigue lives a study of the EIFS technique for fatigue design in the presence of corrosion", Int. J. Fatigue, 26, pp. 71-80 (2004).

42. Kumar, S., Singh, R., Singh, T.P. and Sethi, B.L. "Surface modification by electrical discharge machining, A review", J. Materials Processing Technology, 209, pp. 3675-3687 (2009).

43. Praveen, R. "Study on tool wear for tool movement patterns in micro edm", Science and Tech., 1, pp. 5161 (2012).

44. Kumar, D., Beri, N. and Kumar, A. "Study of overcut during electric discharge machining of hastelloy steel with different", Int. J. Adv. Eng. Tech., 2, pp. 306-312 (2011).

45. Wang, F., Liu, Y., Zhang, Y., Tang, Z., Ji, R. and Zheng, C. "Compound machining of titanium alloy by super high speed EDM milling and arc machining", J. Materials Processing Technology, 214, pp. 531-538. (2014).

46. Singh, S. and Bhardwaj, A. "Review to EDM by using water and powder-mixed dielectric fluid", J. Minerals and Materials Characterization and Engineering, 10, p. 199 (2011).

47. Rao, P.S., Surenrdrababu, B. and Rambabu, M. "Performance of a low cost tabletop die sinker electric discharge machining unit", Int. J. Modern Engineering Research, 3, pp. 1320-1325 (2012).

48. Hafis, S.M., Ridzuan, M.J.M., Farahana, R.N., Ayob, A. and Syahrullail, S. "Paraffinic mineral oil lubrication for cold forward extrusion, effect of lubricant quantity and friction", Tribology International, 60, pp. $111-115$ (2013) 
49. Syahrullail, S., Wira, J.Y., Wan, N.W.B. and Tiong, C.I. "The Effect of sliding speed on friction and wear of RBD palm olein", Applied Mechanics and Materials, 315, pp. 951-955 (2013).

50. Kheang, L. and May, C.Y. "Influence of a lubricant auxiliary from palm oil methyl esters on the performance of palm olein-based fluid", J. Oil Palm Research, 24, pp. 1388-1396 (2012).

51. Ossia, C.V., Han, H.G. and Kong, H. "Response surface methodology for eicosanoic acid triboproperties in castor oil". Tribology International, 42, pp. 50-58 (2009).

\section{Biographies}

Daud Md Razak received his Bachelor degree in Electrical Engineering (Mechatronic) and Master of Technical Vocational Education in the College University Technology Tun Hussein Onn, Malaysia (19992003). He worked at the polytechnic between 2004 till now as a lecturer. In September 2012, he started his graduate studies, Mechanical Engineering and working towards his $\mathrm{PhD}$ degree under the direction of Associate Professor Dr. Syahrullail Samion from the Department of Thermo-Fluids, Faculty of Mechanical Engineering UTM JB. His research related to the new development in the tribology of hip prosthesis/implant includes development of bio-lubricant and CNC EDM research.

Samion Syahrullail obtained his Doctor of Philosophy in Engineering from Kagoshima University, Japan, in 2007. His major field of study is tribology in metal forming. He is currently a Senior Lecturer at the
Department of Thermofluid, Faculty of Mechanical Engineering, Universiti Teknologi Malaysia. His interests include development of bio-lubricant, palm oil research, and fluid mechanics.

Noorawz Nuralizai received her BEng in Aircraft Engineering Technology (Mechanical) from Universiti Kuala Lumpur / Malaysian, Institute of Aviation Technology, in 2012. She is currently pursuing her postgraduate studies (PhD) in Mechanical Engineering at Universiti Teknologi Malaysia, Malaysia. Her research is related to the development of bio-lubricant for automotive industry usage.

Yahy Azlia has been a Senior Lecturer in Universiti Teknologi Malaysia since 1998. He holds a degree in Electro Mechanical Power System and Master's Degree in Electronic Production from Glamorgan University, UK. He holds a doctorate from Loughborough University, UK, specializing in Electronic and Electrical Engineering. His areas of research are analog/digital circuit design, electrical discharge machining, and power supply design.

Sapaw Norzahire holds a doctorate from Universiti Teknologi Malaysia in Resource Chemistry and a PhD in Chemical Engineering, specializing in advanced oxidation processes/photocatalysis and natural products for chemical industry applications. He is the head of the research in pyrolysis of residual palm oil in spent bleaching clay by tubular furnace and analysis of the products by GC-MS in 2008. His interests include development of palm oil lubricant and catalysts for enhanced photodecolorization of dyes. 